\title{
The Effect of Iron on Dislocation Evolution in Model and Commercial Zirconium Alloys
}

DOI:

10.1520/STP159720160068

Document Version

Accepted author manuscript

Link to publication record in Manchester Research Explorer

\section{Citation for published version (APA):}

Topping, M., Harte, A., Frankel, P., Race, C., Sundell, G., Thuvander, M., Andren, H-O., Jädernäs, D., Teiland, P., Romero, J., Darby, E. C., Dumbill, S., Hallstadius, L., \& Preuss, M. (2018). The Effect of Iron on Dislocation Evolution in Model and Commercial Zirconium Alloys. In ASTM International: Zirconium in the Nuclear Industry 18th Symposium ASTM International. https://doi.org/10.1520/STP159720160068

\section{Published in:}

ASTM International: Zirconium in the Nuclear Industry 18th Symposium

\section{Citing this paper}

Please note that where the full-text provided on Manchester Research Explorer is the Author Accepted Manuscript or Proof version this may differ from the final Published version. If citing, it is advised that you check and use the publisher's definitive version.

\section{General rights}

Copyright and moral rights for the publications made accessible in the Research Explorer are retained by the authors and/or other copyright owners and it is a condition of accessing publications that users recognise and abide by the legal requirements associated with these rights.

\section{Takedown policy}

If you believe that this document breaches copyright please refer to the University of Manchester's Takedown Procedures [http://man.ac.uk/04Y6Bo] or contact uml.scholarlycommunications@manchester.ac.uk providing relevant details, so we can investigate your claim.

\section{OPEN ACCESS}




\title{
The Effect of Iron on Dislocation Evolution in Model and Commercial Zirconium Alloys
}

Matthew Topping ${ }^{1}$, Allan Harte ${ }^{1}$, Philipp Frankel ${ }^{1}$, Christopher Race ${ }^{1}$, Gustav Sundell ${ }^{2}$, Mattias Thuvander ${ }^{2}$, Hans-Olof Andrén ${ }^{2}$, Daniel Jadernas ${ }^{3}$, Pia Teiland ${ }^{3}$, Javier Romero ${ }^{4}$, Edward C. Darby ${ }^{5}$, Simon Dumbill ${ }^{6}$, Lars Hallstadius ${ }^{7}$, Michael Preuss ${ }^{1}$

${ }^{I}$ Materials Performance Centre, School of Materials, The University of Manchester, Manchester M13 9PL, UK

${ }^{2}$ Department of Applied Physics, Chalmers University of Technology, SE-412 96 Göteborg, Sweden ${ }^{3}$ Studsvik Nuclear AB, SE 61182 Nyköping, Sweden

${ }^{4}$ Westinghouse Electric Company, Columbia, SC, United States

${ }^{5}$ Rolls-Royce, Derby, DE21 7XX, UK

${ }^{6}$ National Nuclear Laboratory, Sellafield, Seascale, Cumbria, CA20 1PG, UK

${ }^{7}$ Westinghouse Electric Sweden AB, SE 72163, Västerås, Sweden

Keywords: Irradiation-growth, proton-irradiation, BWR, Zircaloy-2, Zr-Fe, BFSTEM, Precipitation, Dislocation analysis

\begin{abstract}
While the evolution of irradiation-induced dislocation loops is well correlated with irradiation-induced growth phenomena, the effect of alloying elements on this evolution remains elusive, especially at low fluences. To develop a more mechanistic understanding of the role of $\mathrm{Fe}$ on loop formation, state-of-the-art techniques have been used to study a proton-irradiated $\mathrm{Zr}-0.1 \mathrm{Fe}$ alloy and proton- and neutronirradiated Zircaloy-2. The two alloys have been irradiated with $2 \mathrm{MeV}$ protons up to 7 dpa at $350{ }^{\circ} \mathrm{C}$ and Zircaloy-2 up to $14.7 \times 10^{25} \mathrm{n} \mathrm{m}^{-2}, \sim 24 \mathrm{dpa}$, in a BWR at $\sim 300^{\circ} \mathrm{C}$.
\end{abstract}

Baseline TEM characterisation showed that the $\mathrm{Zr}_{3} \mathrm{Fe}$ secondary phase particles in the binary system are larger and fewer in number than the $\mathrm{Zr}(\mathrm{Fe}, \mathrm{Cr})_{2}$ and $\mathrm{Zr}_{2}(\mathrm{Fe}, \mathrm{Ni})$ particles in Zircaloy-2. Analysis of the irradiated binary alloy revealed only limited dissolution of $\mathrm{Ze}_{3} \mathrm{Fe}$ suggesting little dispersion of $\mathrm{Fe}$ into the matrix while at the same time a higher a-loop density is observed in comparison to that in Zircaloy-2 at 
equivalent proton dose levels. It was also found that the redistribution of $\mathrm{Fe}$ during irradiation leads to the formation of Fe nanoclusters. A delay in the onset of c-loop nucleation in proton-irradiated Zircaloy-2 compared to the binary alloy was observed. The effect of Fe redistributed from secondary phase particles, due to dissolution, on the density and morphology of a- and c-loops is described. The implication this may have on irradiation-induced growth of $\mathrm{Zr}$ fuel cladding is also discussed.

\section{Introduction}

The irradiation induced growth (IIG) phenomenon is a significant research area for zirconium (Zr) alloys, which are used as cladding and structural materials in fuel assemblies in reactor-cores [1-3]. IIG refers to the volume-conservative shape change, which occurs during neutron irradiation; the cladding expands in the axial direction and shrinks in the radial direction [4]. This growth is one of the main limiting factors in the lifespan of fuel assemblies, which during breakaway growth might also affect oxidation performance considering that a high dimensional change rate has the potential to affect the integrity of the protective oxide layer. Currently, the axial growth of the fuel rods is mitigated via engineering controls to allow for some growth [5]. However, in an effort to reduce costs and increase efficiency, reactor operators are pushing for extended fuel lifetimes, putting extra demands on the core structural materials.

It is widely accepted that the formation of dislocation loops during irradiation is the result of point defects caused by irradiation damage [6-8]. At low fluences, vacancy and interstitial a-loops form with a Burgers vector of $\mathbf{b}=\frac{1}{3}<11 \overline{2} 0>$ and lie on prismatic habit planes [9]. At high fluences, additional vacancy c-loops form that 
have a Burgers vector of $\mathbf{b}=\frac{1}{6}<20 \overline{2} 3>$ and lie on the (0001) plane [10]. The formation of c-loops has been of significant scientific interest due to their appearance coinciding with breakaway growth. Breakaway growth describes the accelerated growth strain that occurs at $\sim 5 \times 10^{25} \mathrm{n} \mathrm{m}^{-2}$ in Zircaloy-2 [6].

The amorphisation and dissolution of secondary phase particles (SPPs) is believed to be of great importance to the microstructural features that evolve during irradiation [11-13]. The $\mathrm{Zr}(\mathrm{Fe}, \mathrm{Cr})_{2}$ type SPPs, found in Zircaloy-2, have been shown to undergo an amorphous transformation under boiling water reactor (BWR) conditions [11]. This amorphous transformation was correlated in [11] to the depletion of Fe, although it has been shown in other studies that amorphisation is not necessary for the dissolution of $\mathrm{Fe}[14,15]$; with similar observations for the $\mathrm{Zr}_{2}(\mathrm{Fe}, \mathrm{Ni}) \mathrm{SPP}$ under neutron-irradiation at intermediate temperatures [13].

The potential effect of alloying elements on c-loop formation has been discussed [1618]. Griffiths and Gilbert demonstrated that the number density of c-loops increases around secondary phase particles (SPPs) that are undergoing irradiation-induced dissolution [13]. It has also been shown that, near SPPs, Fe segregates to c-loops during proton- [18] and neutron-irradiation [19-21]. Christien and Barbu [17] used cluster dynamics to show that the mechanism of formation of c-loops could be linked with the presence of Fe clusters on the basal plane. They demonstrated that in the absence of any Fe clusters breakaway growth did not initiate and that an increased cluster density caused an early onset of breakaway growth. This was reflected in the density of c-loops increasing with increased Fe clusters [17]. However, in a more recent irradiation campaign, growth analysis has shown that increasing $\mathrm{Fe}$ in an alloy 
leads to a decrease in IIG [22].Yagnik et al. used data obtained from the BOR-60 test reactor to investigate a large test matrix of different alloys to monitor growth strain. In $\mathrm{Zr}-\mathrm{Sn}, \mathrm{Zr}-\mathrm{Nb}$ and $\mathrm{Zr}-\mathrm{Sn}-\mathrm{Nb}$ alloys the addition of more Fe led to a decrease in growth strain [22]. Shishov et al. also showed data from the BOR-60 test reactor, which indicated that increased Fe leads to a lower IIG strain in variants of the E635 Nb containing alloy [23].

While most studies have focused on understanding the role of Fe on c-loop formation little work has focused on the effect that Fe might have on a-loop formation. A detailed understanding of the early formation and evolution of a-loops with increasing dose is vital if one considers that c-loop formation is related to a-loop evolution. For instance, it has been proposed that vacancy a-loops are involved in the mechanism for c-loop formation $[24,25]$, supported by an observed anti-correlation for a-loops and cloops seen by Harte et al. [26] and the decrease in a-loop density after c-loop nucleation [25].

The main source for alloying elements to be redistributed during irradiation is the SPPs as they slowly dissolve by leaching out either all or some of their elements into the matrix. A particular interest has been to characterise such irradiation-induced segregation and transmission electron microscopy and atom probe tomography studies have shown that this redistribution results in nano-precipitation and nano-clustering in Zr-Nb type alloys and Zircaloys [24,27-29]. Rod-like structures are the most commonly observed form of irradiation-induced precipitation and are often attributed to fast flux (electron or neutron test reactor conditions) or high temperatures ( $>400$ $\left.{ }^{\circ} \mathrm{C}\right)[27,29]$. 
The aim of this work is to identify the role of Fe on the line density of a-loops and the nucleation of c-loops with a detailed microstructural investigation of both proton- and neutron-irradiated $\mathrm{Zr}$ alloys. A Binary $\mathrm{Zr}-0.1 \mathrm{Fe}$ alloy was proton-irradiated to various dose levels in order to study Fe in isolation from other common alloying elements. A systematic study of low dose material allows for the evolution of irradiation-induced defects that is often missed due to the lack of low dose, in-reactor condition, samples. These observations are compared to proton- and neutron-irradiated Zircaloy-2 in order to draw mechanistic conclusions of industrial relevance.

\section{Experimental Methods}

Proton irradiations were performed using the Michigan Ion Beam Laboratory's 1.7 MeV Tandetron acceleration facility operating at $2 \mathrm{MeV}$ and $350 \pm 9{ }^{\circ} \mathrm{C}$. A current of $\sim 30 \mu \mathrm{A}$ scanned across an area of $16 \mathrm{~mm} \times 10 \mathrm{~mm}$ was maintained throughout the irradiation resulting in a damage rate of $\sim 1.3 \times 10^{-5} \mathrm{dpa} \mathrm{s}^{-1}$. A fully recrystallised binary Zr-0.1Fe (wt.\%) alloy, with a grain size of $\sim 10 \mu \mathrm{m}$, was irradiated from the normal direction to doses of $1.5 \mathrm{dpa}\left(1.348 \times 10^{19}\right), 3.0 \mathrm{dpa}$ $\left(2.752 \times 10^{19}\right)$ and $5.0 \mathrm{dpa}\left(4.549 \times 10^{19}\right)$, with the proton fluence (protons $\left.\mathrm{cm}^{-2}\right)$ provided in brackets for reference. The fully recrystallised Zircaloy-2 (Zr-1.5Sn1.4Fe-0.1Cr-0.06 $\mathrm{Ni}$ [30]) plate material was also irradiated from the normal direction to $2.3 \mathrm{dpa}\left(2.134 \times 10^{19}\right), 4.7 \mathrm{dpa}\left(4.269 \times 10^{19}\right)$ and $7.0 \mathrm{dpa}(6.347 \mathrm{x}$ $10^{19}$ ). The calculation of dose was performed using the SRIM software package with the "Quick" Kinchin and Pease damage calculation [31], in pure $\mathrm{Zr}$ with a displacement energy of $40 \mathrm{eV}$. The profile for the 5.0 dpa sample is shown as an example in Figure 1, after conversion to displacements per atom (dpa). The Bragg 
peak represents the region in the sample that has experienced the highest damage level.

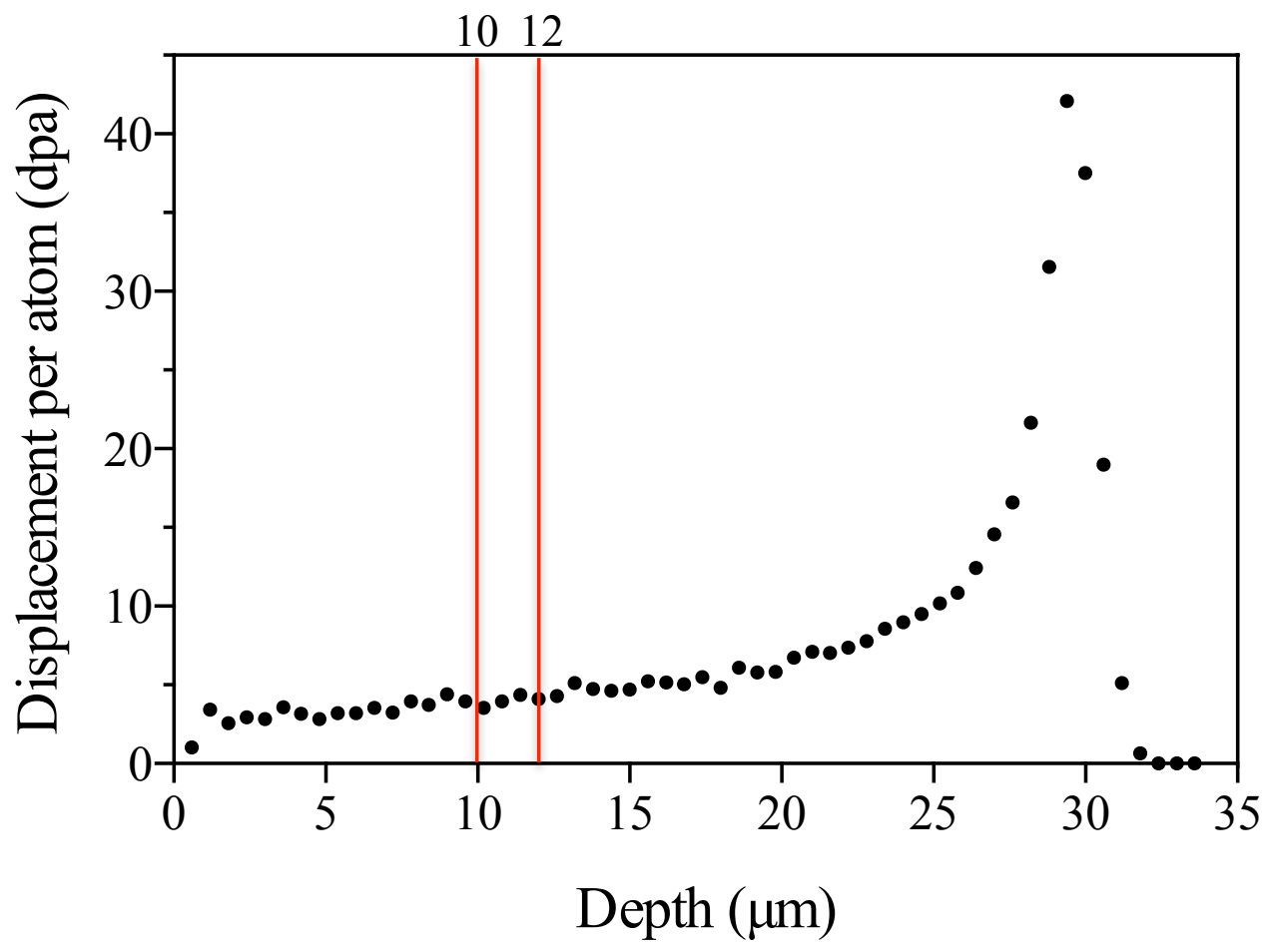

Figure 1. Damage profile generated using SRIM for pure $\mathrm{Zr}$ calculated using the "Quick" method. The simulation was carried out using $2 \mathrm{MeV}$ protons and a displacement energy of $40 \mathrm{eV}$ for $\mathrm{Zr}$. The calculation of dpa was carried out assuming a constant current on the samples of $30 \mu \mathrm{A}$ with a damage rate of $1.263 \times 10^{-5} \mathrm{dpa} \mathrm{s}^{-1}$. The area in-between the red lines represent the region studied using TEM, therefore this profile represents a 5 dpa sample.

The Bragg peak also represents the region where most of the hydrogen will implant. It is expected that the majority of hydrogen will diffuse to the back surface away from the irradiated layer, due to the temperature gradient during the irradiation. It is also difficult to accurately investigate the role of hydrides, as they can form both during irradiation and during sample preparation. Neutron-irradiated Zircaloy-2 TEM foils were supplied by Westinghouse and Studsvik Nuclear, taken from BWR cladding material $\left(280-330^{\circ} \mathrm{C}\right)[32]$. These samples had been irradiated to a fluence of between 8.7 and $14.7 \times 10^{25} \mathrm{n} \mathrm{m}^{-2}$ for $\mathrm{E}>1 \mathrm{MeV}$. Using a conversion of $6.0 \times 10^{24} \mathrm{n} \mathrm{m}^{-2} \mathrm{dpa}^{-1}$ [23], these damage levels correspond to between 14.5 and 24.5 dpa. 
Table 1. Properties of the Zr-0.1Fe binary alloy and Zircaloy-2.

\begin{tabular}{cccccc}
\hline Alloy & $\begin{array}{c}\text { Composition of main } \\
\text { alloying elements } \\
(\mathbf{w t} \%)\end{array}$ & $\begin{array}{c}\text { Average } \\
\text { grain size } \\
(\boldsymbol{\mu m})\end{array}$ & $\begin{array}{c}\text { Metallurgical } \\
\text { state }\end{array}$ & $\begin{array}{c}\text { Main } \\
\mathbf{S P P}(\mathbf{s}) \\
\text { present }\end{array}$ & $\begin{array}{c}\text { Damage } \\
\text { levels } \\
(\mathbf{d p a})\end{array}$ \\
\hline $\mathbf{Z r - 0 . 1 F e}$ & $99.9-\mathrm{Zr}, 0.1-\mathrm{Fe}$ & 10 & $\mathrm{RX}$ & $\mathrm{Zr} 3 \mathrm{Fe}$ & $\begin{array}{c}1.5,3.0, \\
\end{array}$ \\
& & & & & 5.0 \\
Zircaloy-2 & $\begin{array}{c}98.2-\mathrm{Zr}, 1.5-\mathrm{Sn}, \\
0.14-\mathrm{Fe}, 0.1-\mathrm{Cr},\end{array}$ & 10 & $\mathrm{RX}$ & $\mathrm{Zr}(\mathrm{Fe}, \mathrm{Cr})_{2}$ & $2.3,4.7$, \\
& $0.06-\mathrm{Ni}$ & & & $\mathrm{Zr}_{2}(\mathrm{Fe}, \mathrm{Ni})$ & 7.0 \\
& & & & \\
\hline
\end{tabular}

TEM foils were prepared from the proton-irradiated material via twinjet electropolishing using an electrolyte of $10 \%$ perchloric acid in methanol at $-40{ }^{\circ} \mathrm{C}$ for the $\mathrm{Zr}-0.1 \mathrm{Fe}$ alloy. The proton-irradiated Zircaloy-2 material was polished with an electrolyte of $10 \%$ perchloric acid and $20 \%$ 2-butoxyethanol in ethanol at $0{ }^{\circ} \mathrm{C}$. Red lines in Figure 1 illustrate the target region for TEM sample preparation, to allow for an even damage profile across the sample. To achieve this, $\sim 12 \mu \mathrm{m}$ was electropolished from the irradiated surface. This was confirmed using a Keyence VKX200K 3D Laser Scanning Microscope, after which the irradiated face was protected with acid-resistant lacquer and then polished to perforation from the non-irradiated face.

A procedure for anodic dissolution to extract SPPs from the matrix was developed by Toffolon-Masclet et al. [33] and exploited in this work. SPPs were removed from non-irradiated $\mathrm{Zr}-0.1 \mathrm{Fe}$ material in order to assess the chemistry without matrix contributions. The electrolyte used was $10 \%$ perchloric acid in methanol. After dissolution, the particles were separated from other electrolytic products in a centrifuge and the extracted particles were deposited onto a thin amorphous carbon film supported by a copper grid and analysed via energy dispersive spectroscopy (EDS) point spectra in a $200 \mathrm{keV}$ FEI Tecnai G2 20 S/TEM. Electron backscatter 
diffraction (EBSD) was performed on SPPs in a bulk $\mathrm{Zr}-0.1 \mathrm{Fe}$ sample to confirm the crystal structure (not shown) of the $\mathrm{Zr}_{3} \mathrm{Fe}$ SPP [34]. An FEI Quanta 650 FEG SEM operating at $20 \mathrm{kV}$ accelerating voltage and a step size of $100 \mathrm{~nm}$ was used to collect the EBSD data, with the analysis carried out using the AZtecHKL software package.

All of the bright-field scanning transmission electron microscopy (BF-STEM) and spectral imaging was performed using a G2 80-200 kV spherical aberration-corrected FEI Titan microscope. The microscope was operated at $200 \mathrm{kV}$ with a probe current of 600 pA. This microscope is equipped with the FEI ChemiSTEM ${ }^{\mathrm{TM}}$ system, which consists of four windowless EDS detectors in close proximity to the sample to give a collection angle of $0.7 \mathrm{srad}$. The chemical maps obtained are individually scaled and therefore comparing Fe content between samples is not possible by the images alone. BF-STEM imaging has been used exclusively in this work. The convergent nature of the beam in STEM allows for a reduction in strain contrast caused by features in the matrix such as bend contours and SPP misfit strain, which enables clearer imaging of dislocations in close proximity to secondary phase particles, as demonstrated previously [26].

Invisibility criteria experiments were performed to understand the nature of irradiation-induced defects. This analysis is based on the principle that if the dot product of the Burgers vector (b) and the diffraction vector (g) is equal to zero, the vectors are perpendicular, then the strain contrast will be invisible [35,36]. One must also be aware of the line direction of the dislocation. In a loop the line direction is always changing, which makes it difficult to accurately achieve the invisibility criteria. Using the known Burgers vectors, $\mathbf{b}=\frac{1}{3}<11 \overline{2} 0>$ for a-loops [9] and 
${ }_{6}^{1}<20 \overline{2} 3>$ for c-loops [24,37], specific diffraction conditions were targeted. To image a-loops and pyramidal loops BF-STEM images were taken on the $<11 \overline{2} 0\rangle$ zone axis as diffraction contrast from multiple $\mathbf{g}$ vectors contribute to the image. It also allows for the observation of the tilt of the pyramidal loops from the c-axis. To determine the a-loop Burgers vector, BF STEM images were obtained parallel to the $\mathbf{g}$ $=0002$ and $\mathbf{g}=1 \overline{1} 00$ systematic row. c-loops were imaged at $\mathbf{g}=0002$ as a-loops are invisible in this condition, which allows for their easy recognition and counting.

Atom probe tomography (APT) samples were fabricated using the conventional in situ lift-out method [38], with a combined focused ion beam scanning electron microscope (FIB-SEM). Tips were prepared by annular milling with a $\mathrm{Ga}^{+}$beam at 30 $\mathrm{kV}$ acceleration voltage with gradually decreasing currents and radii, followed by a final low-voltage cleaning step at $2 \mathrm{kV}$ to minimize surface damage. Atom probe analysis was performed using an Imago LEAP 3000X HR system, operated in laserpulsed mode with a green $(\lambda=532 \mathrm{~nm})$ laser. The pulsing rate during experiments was $200 \mathrm{kHz}$ and the pulse energy was varied between 0.1-0.4 $\mathrm{nJ}$. The base temperature of the tips during analysis was held between $40-70 \mathrm{~K}$ and the pressure in the chamber was approximately $10^{-9} \mathrm{~Pa}$. APT reconstructions were performed using the IVAS 3.6.8 software, using an evaporation field of $28 \mathrm{~V} / \mathrm{nm}$ combined with either the default $k$-factor of 3.3 or tip shape estimates from SEM micrographs of the analysed tips. As the basal pole was often visible in the desorption maps with well defined atomic planes resolved [39], calibration of the reconstructions could be made using a $d$-spacing of $2.58 \AA(c / 2)$. Only minor modifications to the default reconstruction parameters were needed for good agreement with the known lattice spacing along the $c$ axis. APT analyses was carried out on 3 and 9 cycle Zircaloy-2 
material, neutron-irradiated to the same conditions as the TEM specimens mentioned above.

\section{Results}

Two types of SPP were detected in the anodic dissolution of the $\mathrm{Zr}-0.1 \mathrm{Fe}$ material, as shown in Figure 2. SPPs of diameter $>\sim 2 \mu \mathrm{m}$ had a Zr:Fe ratio of $\sim 3: 1$ and SPPs of diameter $\sim 200 \mathrm{~nm}$ had a ratio $\sim 2: 1$. By comparing simulated with experimental diffraction patterns, using EBSD, the crystal structure of the large SPPs was verified as the $\mathrm{Zr}_{3} \mathrm{Fe}$ orthorhombic phase. In the matrix the smaller SPPs are assumed to be $\mathrm{Zr}_{2} \mathrm{Fe}$ and were only observed during the particle extraction analysis. Therefore it is believed that their influence on microstructure evolution is negligible and so they will not be discussed further in this work. Hydrides have also been observed in both alloy systems, however they will not be discussed further as the influence of hydrides on the dislocation structure is beyond the scope of this work. The regions of the samples studied in this work were not in the vicinity of hydrides.

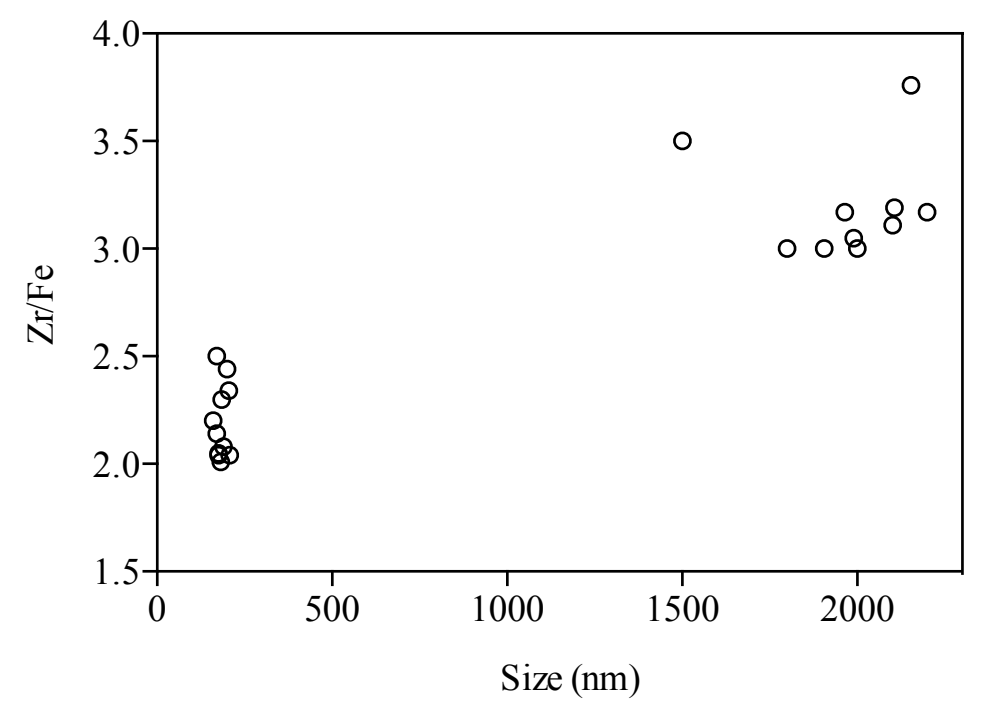

Figure 2. Ratio of $\mathrm{Zr} / \mathrm{Fe}$ determined by STEM-EDS vs size (diameter) of extracted particles from a non-irradiated $\mathrm{Zr}-0.1 \mathrm{Fe}$ alloy. Note two clear regimes of particle can be seen. The largest particles have a $\mathrm{Zr} / \mathrm{Fe}$ ratio of $3: 1$. 
Figure 3 is a BF STEM image of a $\mathrm{Zr}_{3} \mathrm{Fe}$ SPP at a grain boundary obtained from the $<11 \overline{2} 0>$ zone axis. The red boxes indicate the areas in which Figure 4(a) and (c) were acquired. Figure 4(a) and (c) are BF-STEM images obtained from the $<11 \overline{2} 0\rangle$ zone axis in a $\mathrm{Zr}-0.1 \mathrm{Fe}$ alloy proton-irradiated to $1.5 \mathrm{dpa}$, both at the same magnification. Part (a) is taken close to a $\mathrm{Zr}_{3} \mathrm{Fe}$ SPP and (c) is $\sim 1 \mu \mathrm{m}$ away from any SPP. Tilted features can be seen close to the SPP in (a), which align in rows parallel to the trace of the basal plane. The maximum distance in which Fe segregation in the matrix was detected from an SPP at this dose is $535 \mathrm{~nm}$. The a-loops observed are elliptical with the major axis elongated in the c-axis. The mean length of the major axis of a-loops around the SPP is $16.1 \pm 1.8 \mathrm{~nm}$, which are significantly smaller than the a-loops seen away from the SPP in $(\mathrm{c}), 25.2 \pm 1.9 \mathrm{~nm}$. Away from the SPP no tilted defects were observed. Spectral imaging was performed at the $<11 \overline{2} 0>$ zone axis and the Fe map of Figure 4(a) is displayed in (b). It is clear that there is Fe segregation to all of these tilted features. Figure $4(d)$ is a line scan taken from the regions highlighted by arrows in (a) and (c). This graphic demonstrates that at $1 \mu \mathrm{m}$ from a $\mathrm{Zr}_{3} \mathrm{Fe} \mathrm{SPP}$, at the same damage level, there is no Fe segregation detected at defect structures. The same effect of Fe redistribution was seen in the 3 and 5 dpa samples. However it is not possible to comment on the effect of dpa on the size of the affected region as this would require the analysis of similarly sized SPPs, which has not been possible in the studied samples. 


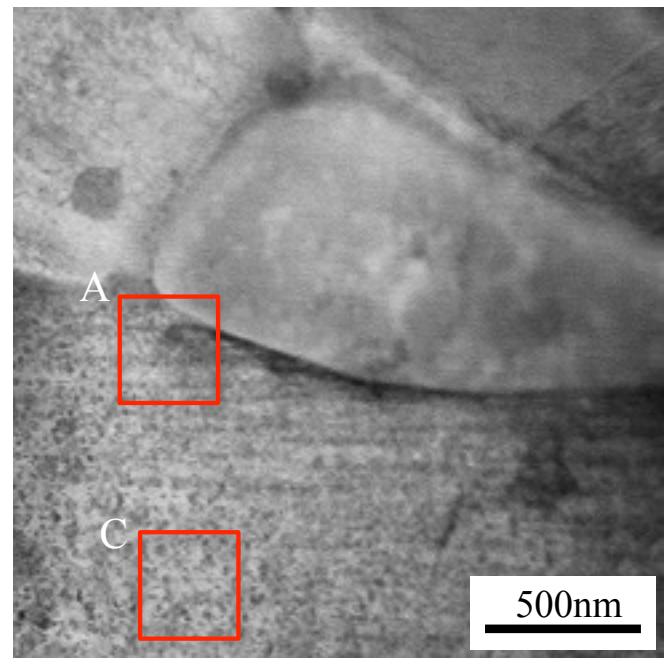

Figure 3. BF-STEM image of 1.5 dpa proton-irradiated $\mathrm{Zr}-0.1 \mathrm{Fe}$ sample. A large $\mathrm{Zr}_{3} \mathrm{Fe}$ SPP can be seen at a grain boundary. The red boxes indicate the regions investigated in Figure 4. A: Figure 4(a), C: Figure 4(c).
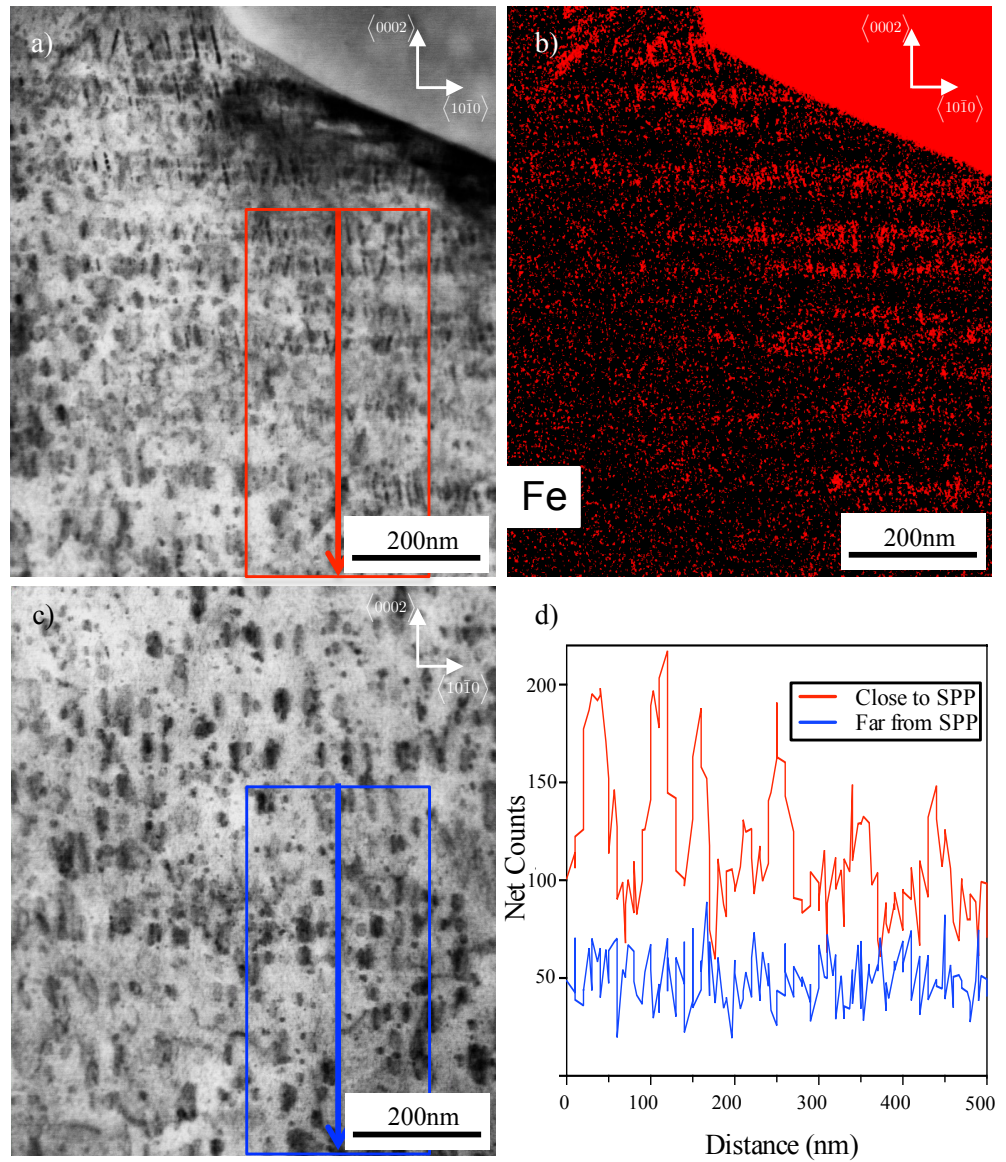

Figure 4. Defect study in a $\mathrm{Zr}-0.1 \mathrm{Fe}$ alloy proton-irradiated to $1.5 \mathrm{dpa}$. a) BF-STEM image taken at $<11 \overline{2} 0>$ zone axis. $\mathrm{A} \mathrm{Zr}_{3} \mathrm{Fe}$ SPP can be seen in the top right corner of the image. Close to the SPP tilted features can be seen aligning in rows parallel to the basal plane. b) Fe map of (a) taken at $<11 \overline{2} 0>$ zone axis. Fe segregation can be seen at the positions of the tilted features in (a). c) BFSTEM image taken at $\langle 11 \overline{2} 0\rangle$ zone axis $>1$ um away from any SPPs. d) Line scan of (a) + (c) showing Fe segregation. The line scans are displayed in net counts. The red line represents (a) and the blue line represents (c). No Fe segregation is seen in (c) so any local variations in Fe counts are considered noise. 
Figure 5 shows a dislocation invisibility study using BF-STEM imaging, which has been carried out on the tilted features at 1.5 (a)-(d) and 5 dpa (e)-(h) in the $\mathrm{Zr}-0.1 \mathrm{Fe}$ alloy. (a) and (e) were obtained from the $<11 \overline{2} 0>$ zone axis, (b) and (f) were taken parallel to the $\mathbf{g}=0002$ and (c) and (g) parallel to the $\mathbf{g}=1 \overline{1} 00$ systematic row. For both $\mathbf{g}=0002$ and $\mathbf{g}=1 \overline{1} 00$, images were taken $\sim 10^{\circ}$ away from the $<11 \overline{2} 0>$ zone axis. At 1.5 dpa the tilted defects are visible at the $\langle 11 \overline{2} 0\rangle$ zone axis and at $\mathbf{g}=$ 0002 but invisible at $\mathrm{g}=1 \overline{1} 00$, suggesting that these features are dislocations with a Burgers vector that contains a c-component. The same alloy, proton-irradiated to the higher dose of $5 \mathrm{dpa}$, showed similar tilted defects, however these remained visible at $\mathbf{g}=1 \overline{1} 00$, suggesting a change in their nature from dislocations at low dose to nanoprecipitates or rods at higher dose. Figure 5(d) and (h) show the Fe maps for the 1.5 and 5 dpa $\mathrm{Zr}-0.1 \mathrm{Fe}$ sample respectively. Fe is clearly identified at both proton doses. The Fe at the tilted defect at 5 dpa looks more diffuse than in $1.5 \mathrm{dpa}$. It is not clear if this effect is real or an artefact of the sample thickness. The area studied in the 5 dpa sample was the thinnest region of the sample that contained an SPP. The thickness of the sample may also explain why no diffraction spots were observed of the irradiation induced precipitation. 

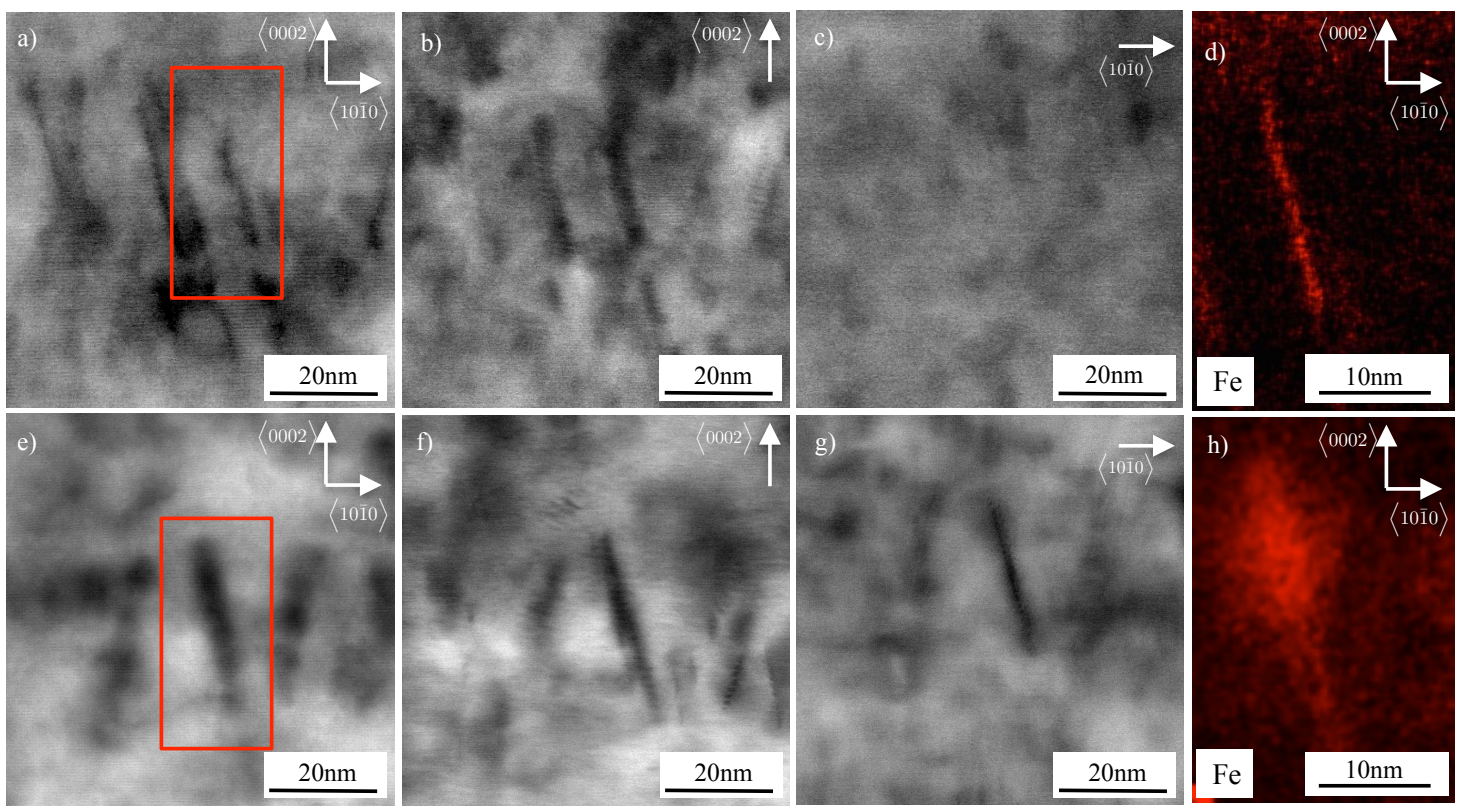

Figure 5. Invisibility study of tilted defects in a binary Zr-0.1Fe alloy. (a)-(c) BF-STEM images from a 1.5 dpa proton-irradiated $\mathrm{Zr}-0.1 \mathrm{Fe}$ sample. (e)-(g) BF-STEM images from a 5 dpa proton-irradiated $\mathrm{Zr}$ $0.1 \mathrm{Fe}$ sample. (a)+(e) BF-STEM images from the $<11 \overline{2} 0>$ zone axis. (b)+(f) BF-STEM images parallel to the $g=0002$. $(\mathrm{c})+(\mathrm{g})$ BF-STEM images parallel to the $\mathrm{g}=10 \overline{1} 0$. Note that the titled feature in the 1.5 dpa sample becomes invisible at $\mathrm{g}=10 \overline{1} 0$. (d) $+(\mathrm{h})$ Fe maps of tilted defects. Defects indicated with red box in (a)+(e).

Neutron-irradiated Zircaloy-2 samples were analysed to provide industrial context to the observations in the proton-irradiated material. Similar Fe containing rods have also been observed in 7 dpa proton- and 14.7 dpa neutron-irradiated Zircaloy-2, Figure 6(a) and (b) respectively. Both images were taken at the same magnification and at $\langle 11 \overline{2} 0\rangle$ zone axis. The rods in both of these samples are similar in appearance to the 5 dpa binary alloy material, with the long axis of the rod tilted $\sim 15^{\circ}$ from $<0001>$. These tilted rods were also seen in the 24.5 dpa neutron-irradiated Zircaloy-2. The average length of the rods decreases in proton-irradiated Zircaloy-2 between $2.3 \mathrm{dpa}$ and $4.7 \mathrm{dpa}$ from $23 \mathrm{~nm}$ to $7 \mathrm{~nm}$. 

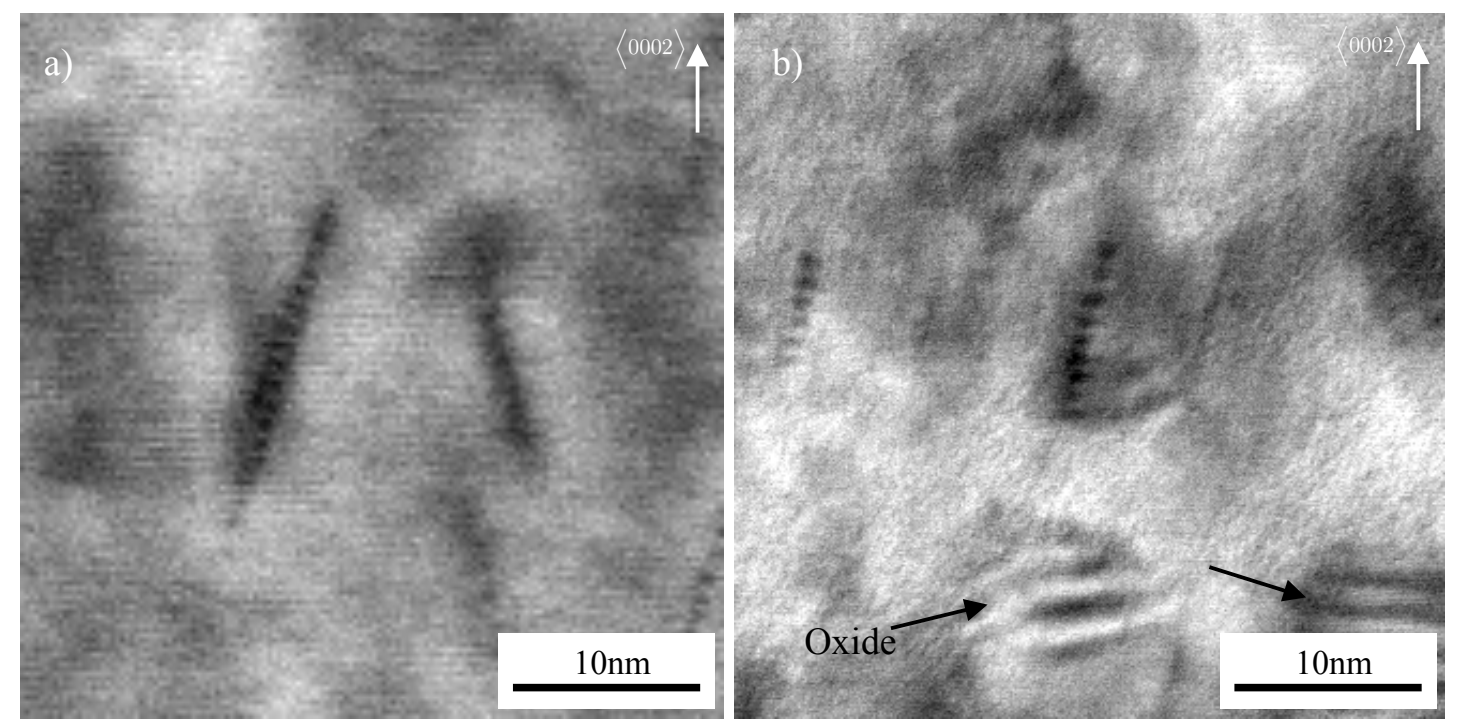

Figure 6. BF-STEM images taken parallel to the $\mathrm{g}=0002$ of precipitates in different irradiation conditions in Zircaloy-2, demonstrating the relevance of these features found in the proton-irradiated materials. a) Proton-irradiated to $7 \mathrm{dpa}$. b) Neutron-irradiated to $14.5 \mathrm{dpa}$. Oxide fringes, indicated by the black arrows, in the image are indicated. These are due to surface oxidation.

Figure 7 shows chemical segregation and c-loop decoration in neutron-irradiated Zircaloy-2 using both spectral imaging and APT. Figure 7(a) and (b) were obtained from the $\langle 11 \overline{2} 0>$ orientation and show discontinuous $\mathrm{Fe}$ and $\mathrm{Cr}$ segregation parallel to the basal trace in close proximity to a $\mathrm{ZrFeCr}$-type SPP in Zircaloy-2, neutron-irradiated to $\sim 23 \mathrm{dpa}$. The segregation coincides with the position of c-loops around the SPP. Figure 7(c) is an APT reconstruction of a tip taken from Zircaloy-2, neutron-irradiated to $\sim 15$ dpa. A ZrFeCr-type SPP is contained in the volume, and discontinuous segregation of $\mathrm{Fe}$ and $\mathrm{Cr}$ is seen to align in parallel planes. Figure 7 (d) is an APT reconstruction of a tip taken from Zircaloy-2 after a neutron dose of $\sim 40$ dpa and shows a loop-like structure decorated with Fe and $\mathrm{Cr}$. The Fe segregation is continuous around the length of the loop and $\mathrm{Cr}$ forms discrete clusters. 


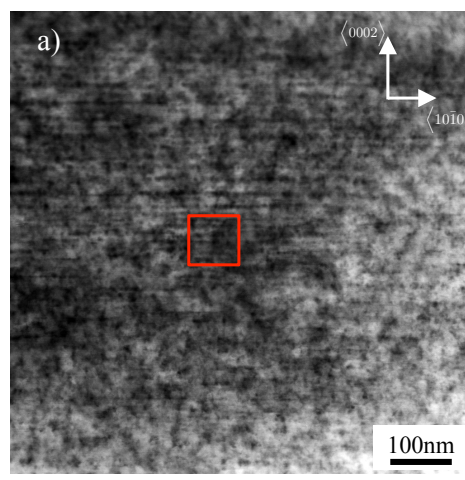

$100 \mathrm{~nm}$

d)

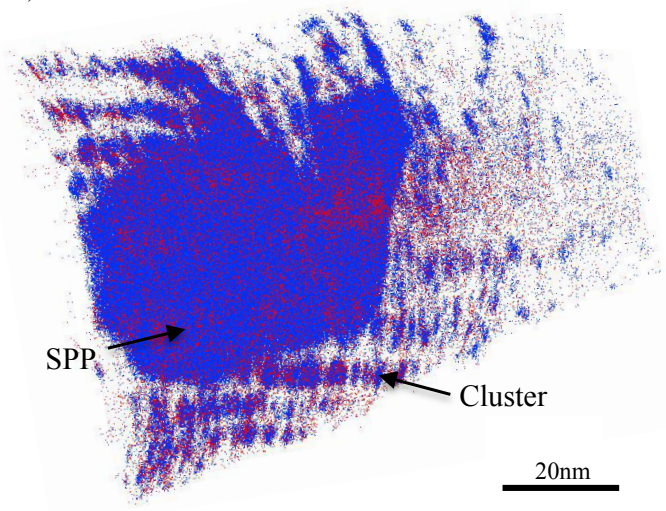

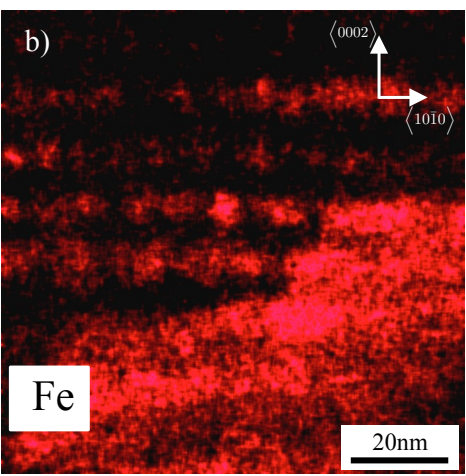

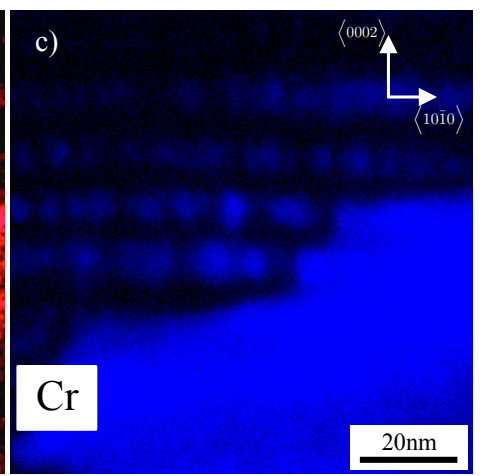

e)

- $\mathrm{Fe}$

- $\mathrm{Cr}$

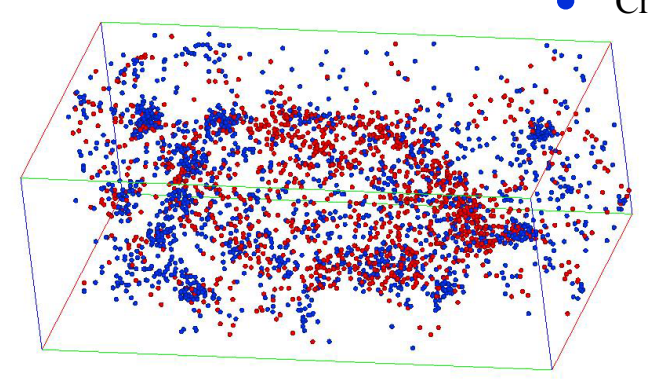

Figure 7. c-loop decoration in neutron-irradiated Zircaloy-2. a) BF-STEM image from the $<11 \overline{2} 0>$ zone axis, neutron-irradiated to $14.5 \mathrm{dpa}$. The red box indicates the region spectral imaging was carried out (b)+(c). b) Fe map from the $\langle 11 \overline{2} 0\rangle$ zone axis showing Fe segregation in clusters along the trace of the basal plane. c) Cr map from the $\langle 11 \overline{2} 0\rangle$ zone axis showing $\mathrm{Cr}$ segregation in clusters along the trace of the basal plane. Cr clusters are coherent with Fe clusters seen in (b). d) APT reconstruction of 3-cycle Zircaloy-2 shows the distribution of $\mathrm{Fe}$ (red) and $\mathrm{Cr}$ (blue) around a dissolving SPP. Note the disc-shape of the clusters, which are aligned on parallel planes through the matrix.e) APT reconstruction of 9-cycle Zircaloy-2 shows segregation of $\mathrm{Fe}$ (red) and $\mathrm{Cr}$ (blue) at and around a $<\mathrm{c}>$ loop in the matrix.

A comparison of a-loop morphology in Zircaloy-2 and Zr-0.1Fe proton-irradiated to 4.7 and 5 dpa, respectively, is shown in Figure 8. BF-STEM images and chemical data were collected at the $\langle 11 \overline{2} 0\rangle$ zone axis at the same magnification. The mean length of the a-loop major axis in 4.7 dpa Zircaloy- 2 is $7.8 \pm 3 \mathrm{~nm}$ and $25.7 \pm 1 \mathrm{~nm}$ in 5 dpa $\mathrm{Zr}-0.1 \mathrm{Fe}$. Further, the a-loops in (a) are more organised than those in (b). Fe segregation is observed to coincide with the a-loops along basal traces in the Zircaloy2 material as shown in Figure 8(c). Such segregation is not observed in the $\mathrm{Zr}-0.1 \mathrm{Fe}$ at similar doses, as demonstrated in the line scan in the $<0002>$ direction shown in Figure 8(d). No clear Fe segregation was detected in the line scan of (b), therefore any local changes in the Fe counts are considered noise. 

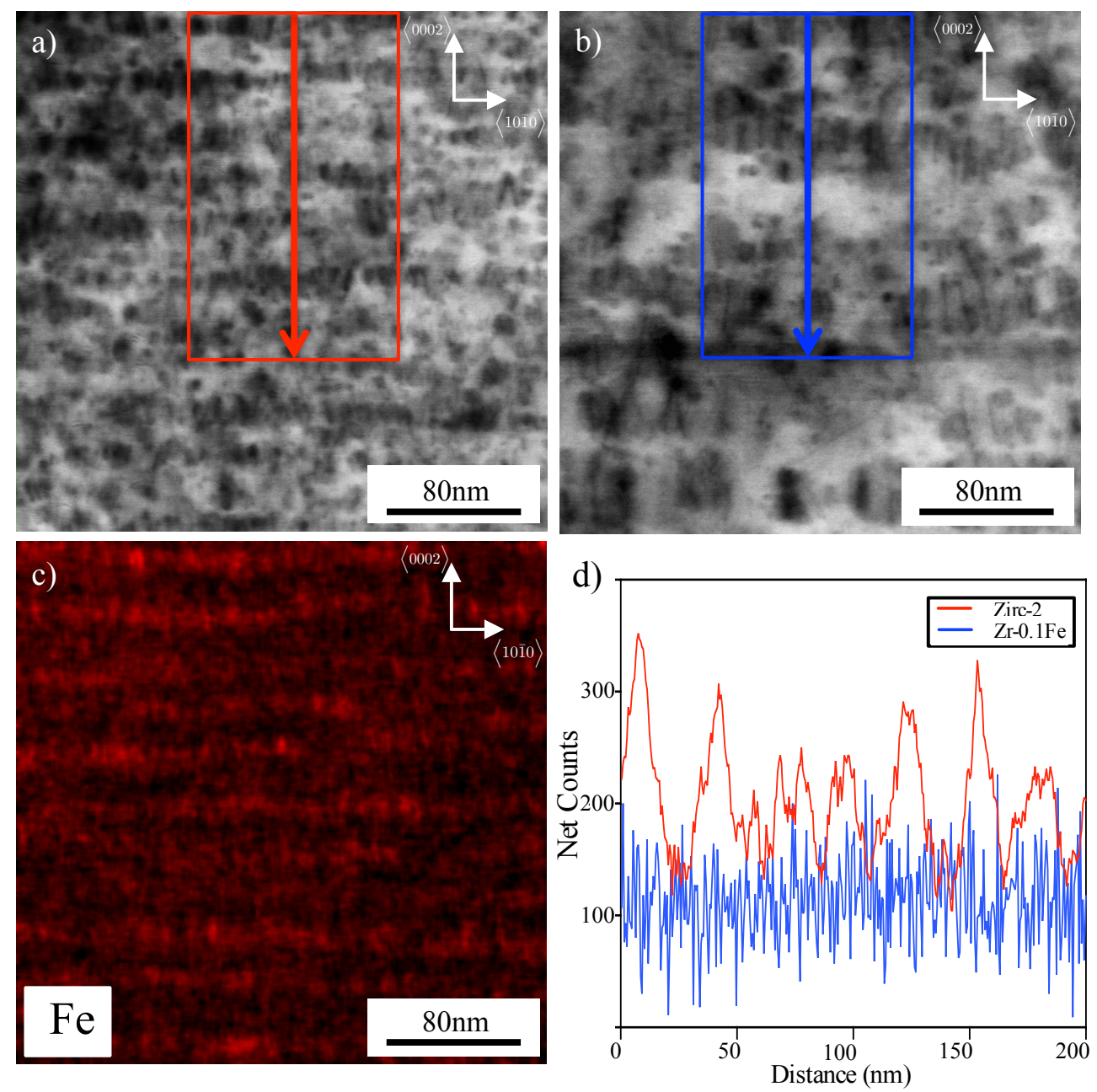

Figure 8. Comparison of Fe segregation in proton-irradiated Zircaloy-2 and Zr-0.1Fe. All images taken from the $\langle 11 \overline{2} 0\rangle$ zone axis and at the same magnification. a) BF-STEM image of the 4.7dpa protonirradiated Zircaloy-2 sample. Alignment of a-loops can be seen parallel to the basal plane. b) BFSTEM image of the 5dpa proton-irradiated $\mathrm{Zr}-0.1 \mathrm{Fe}$ sample. c) Fe map of (a). Fe segregation to tilted precipitates can be seen aligning in the trace of the basal plane. d) Line scan of (a)+(b) showing Fe segregation. The line scans are displayed in net counts. The red line represents (a) and the blue line represents (b). No Fe segregation seen in (b), local variation in Fe counts considered noise.

A comparison of a-loop line density $\left(\varrho_{\mathrm{LD}}\right)$ and the length of the a-loops major axis in proton-irradiated Zircaloy-2 and Zr-0.1Fe can be seen in Figure 9 (a) and (b) respectively. The proton-irradiated Zircaloy-2 material shows a decrease in a-loop size as the proton dose increases, whereas in the $\mathrm{Zr}-0.1 \mathrm{Fe}$ material there is a slight increase in size. The overall $\varrho_{\mathrm{LD}}$ of a-loops in the $\mathrm{Zr}-0.1 \mathrm{Fe}$ alloy remains larger than in Zircaloy-2 at all proton doses. Figure 9(d) shows c-loop $\varrho_{\mathrm{LD}}$ as a function of dpa for 
these samples. The proton dose at which c-loops nucleate is lower for the $\mathrm{Zr}-0.1 \mathrm{Fe}$ alloy than Zircaloy-2. The size of a-loops in the neutron-irradiated Zircaloy-2 is not discussed here as those samples only covered a very high dpa parameter space. A detailed analysis of these samples including a comparison to proton irradiated Zircaloy-2 samples can be found in [26], which demonstrates good agreement regarding loop size and density between proton and neutron irradiated samples.
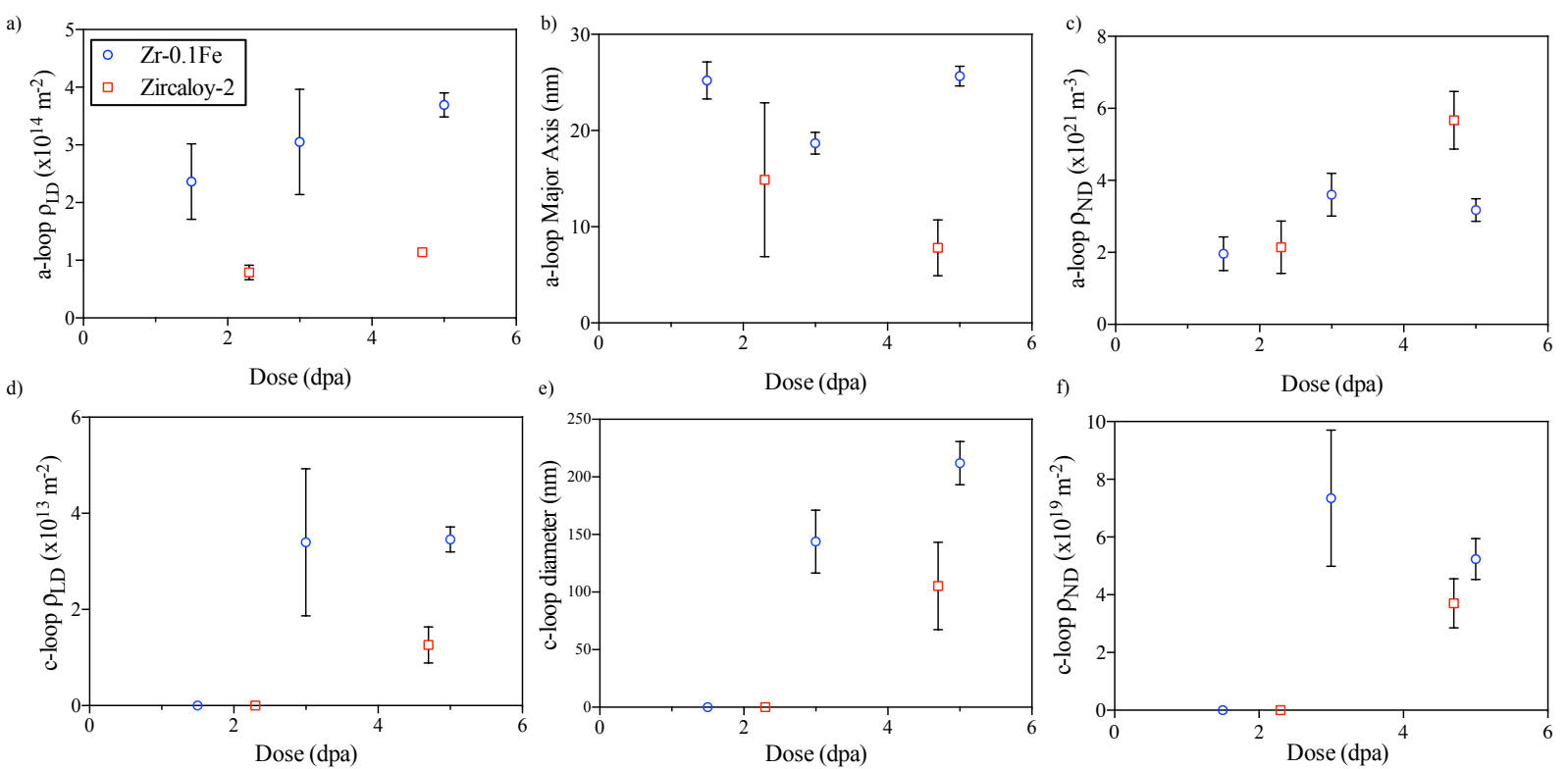

Figure 9. In all graphs: red squares represent proton-irradiated Zircaloy-2, blue circles represent proton-irradiated $\mathrm{Zr}-0.1 \mathrm{Fe}$. Error bars represent standard deviation in measurements. A lack of error bars is due to the error being too small to be seen due to the y-axis scale. a) a-loop line density vs dpa. b) Major axis of elliptical a-loop vs dpa. c) a-loop number density vs dpa. d) c-loop line denisty vs dpa. e) c-loop diameter vs dpa. f) c-loop number density vs dpa. 


\section{Discussion}

The present work informs four essential observations:

1. There is more Fe redistribution in Zircaloy-2 than in $\mathrm{Zr}-0.1 \mathrm{Fe}$ at similar dose levels

2. Fe segregates to pyramidal dislocation loops, which act as nucleation sites for nano-preciptates as matrix Fe content increases.

3. Fe nano-preciptates align with a-loops in the basal plane trace.

4. There is a lower a-loop line density in Zircaloy-2 than in Zr-0.1Fe and a longer delay to the onset of c-loop nucleation.

These observations will be discussed, in the following sections, within the context of data available in the literature. The correlation of the nano-precipitation with a decrease in dislocation density is of major interest and the potential link of this effect on IIG will be discussed.

\section{Nature of Tilted Defects}

The SPPs in the binary $\mathrm{Zr}-\mathrm{Fe}$ alloys are predominantly $\mathrm{Zr}_{3} \mathrm{Fe}$ in composition. During proton irradiation these SPPs show dissolution of Fe into the matrix as seen in Figure 4(b). In neutron-irradiated $\mathrm{Zr}$-Sn alloys with varying Fe contents, the $\mathrm{Zr}_{3} \mathrm{Fe}$ SPPs have been reported as stable under irradiation with respect to dissolution and no amorphisation has been reported [14,40]. However Motta and Howe et al. have demonstrated that $\mathrm{Zr}_{3} \mathrm{Fe}$ undergoes an amorphous transformation during $0.9 \mathrm{MeV}$ electron irradiation between 28-220K [41] and under heavy ion irradiation between 35-725K [42]. During proton irradiation carried out in the present work no amorphisation of the $\mathrm{Zr}_{3} \mathrm{Fe}$ SPPs was observed up to the maximum dose (5 dpa), as only crystalline electron diffraction patterns were collected across $\mathrm{Zr}_{3} \mathrm{Fe}$ SPPs at this 
dose. This suggests that amorphisation is not a necessary requirement for SPP dissolution. The study of the amorphisation transformation of these SPPs has not been conducted as part of this work, as the main aim is to address the effect of the redistributed Fe. A detailed study of the SPPs, and the segregation of the other major alloying elements in the proton-irradiated Zircaloy-2 samples, can be found elsewhere [43].

Similar observations have been reported for the $\mathrm{Zr}(\mathrm{Fe}, \mathrm{Cr})_{2} \mathrm{SPP}$ in Zircaloy-2 neutron irradiated between $325-350^{\circ} \mathrm{C}[14]$, proton irradiations at $\sim 350^{\circ} \mathrm{C}[15,44]$ and also in Excel alloy under heavy-ion irradiation at $400^{\circ} \mathrm{C}$ [45]. This is likely due to the use of irradiation temperatures above that of the critical temperature for amorphisation, allowing competing thermal recovery processes to take place that prevent the defective structure from undergoing the crystalline-to-amorphous transformation $[42,46]$. Issues still remain in utilising proton-irradiations to mimic all aspects of microstructural changes observed in neutron-irradiated materials. However the $50^{\circ} \mathrm{C}$ temperature offset used in proton-irradiations appears to be acceptable when comparing the dislocation loops formed between the two irradiation species. More studies are still needed to fully understand the comparison of proton- and neutronirradiated materials.

The presence of tilted dislocation loops has been reported in neutron-irradiated Zircaloy-2 by Griffiths et al., irradiated in the Experimental Breeder Reactor II (EBRII) at $371-437^{\circ} \mathrm{C}[25]$. Due to their presence in Fe-containing alloys, mainly the Zircaloys, with evidence of Fe redistribution, it was theorised that the tilted loops are stabilised by $\mathrm{Fe}$ [29]. This has been confirmed in the present work as shown in Figure 4(b). Woo et al. described similar features as precipitates in Zircaloy-2, neutron- 
irradiated in EBR-II to $~ 3 \mathrm{dpa}$, using a reported conversion factor from fluence to dpa of $4.4 \times 10^{24} \mathrm{n} \mathrm{m}^{-2}$, at $\sim 600{ }^{\circ} \mathrm{C}$ [27]. In 0.1 dpa electron-irradiated Zircaloy-2 at $300^{\circ} \mathrm{C}$, Griffiths et al. referred to these tilted features as non-basal plane c-component defects and reported a Burgers vector of $\frac{1}{3}<11 \overline{2} 3>$ with a habit plane on, or close to, pyramidal planes [47]. One may therefore consider high damage rates or elevated temperatures to be a contributing factor to the formation of such features. However, we also observe the tilted defects in Zircaloy-2 after exposure to BWR conditions, Figure 6(b). Hence, the evolution of these features does have significant industrial importance.

Figure 5 shows Burgers vector analysis performed on 1.5 and 5 dpa proton-irradiated Zr-0.1Fe alloy using BF-STEM imaging under different diffraction conditions. Determining the nature of the tilted features and how they evolve is vital in order to further understand their role in relation to other defects and, ultimately, irradiationinduced growth. In the $\mathrm{Zr}-0.1 \mathrm{Fe} 1.5 \mathrm{dpa}$ sample the tilted defects remain visible at $\mathbf{g}=$ 0002 indicating they have a different Burgers vector to that of a-loops. These features become invisible at $\mathbf{g}=1 \overline{1} 00$ and lie on a pyramidal plane, consistent with the $<\mathrm{c}+\mathrm{a}>-$ loops with a Burgers vector of $\frac{1}{3}<11 \overline{2} 3>$ as described by Griffiths [47]. At 5 dpa the tilted features remain visible at all tested diffraction conditions, which suggests that nano-precipitates have formed now. The presence of Fe at these features at 1.5 and 5 dpa could suggest that there is a critical point at which enough $\mathrm{Fe}$ has segregated to the pyramidal loops to form precipitates. Due to the thickness of the foil and the small size of these features it was not possible to track a change in rod composition as a function of proton dose during the STEM analysis or carry out diffraction pattern analysis and APT analysis failed on the $\mathrm{Zr}-0.1 \mathrm{Fe}$ samples. 
While the composition of the irradiation-induced nano-precipitates could not be confirmed in the present work due to their small size in a correspondingly large matrix, one possibility is that they are $\mathrm{Zr}_{3} \mathrm{Fe}$, as it is considered to be the stable phase in $\mathrm{Zr}$ when the $\mathrm{Fe} / \mathrm{Cr}$ is $>4$ [14]. $\mathrm{Zr}_{3} \mathrm{Fe}$ has also been shown to precipitate in Zircaloy2 after being exposed to BWR conditions [46]. $\mathrm{Zr}_{5} \mathrm{Sn}_{3}$ precipitates have been reported in Zircaloy-2 under high flux, fluence and temperature conditions [27], however the lack of $\mathrm{Sn}$ in the binary alloys excludes the possibility of this phase forming.

\section{Effect of irradiation induced precipitation on dislocation structure}

At similar proton dose levels, Zircaloy-2 displays strong Fe segregation to the trace of the basal plane whereas the $\mathrm{Zr}-0.1 \mathrm{Fe}$ sample does not when $>1 \mu \mathrm{m}$ from an SPP, Figure 8 . This is assumed to be primarily due to the difference in type, size and volume fraction of SPPs in each alloy. The SPPs present in Zircaloy-2 are $\mathrm{Zr}(\mathrm{Fe}, \mathrm{Cr})_{2}$ and $\mathrm{Zr}_{2}(\mathrm{Fe}, \mathrm{Ni})$ and their behaviour under irradiation has been well documented $[11,13,48-50]$. The relevance for this work is the observed dissolution of alloying elements from SPPs in Zircaloy-2 under proton- [15] and neutron-irradiation [13]. The $\mathrm{Zr}_{3} \mathrm{Fe}$ SPP are reported to be stable under irradiation conditions in comparison to $\mathrm{Zr}(\mathrm{Fe}, \mathrm{Cr})_{2}$ and $\mathrm{Zr}_{2}(\mathrm{Fe}, \mathrm{Ni})$ [14]. In addition, the $\mathrm{Zr}_{3} \mathrm{Fe}$ SPPs in $\mathrm{Zr}-0.1 \mathrm{Fe}$ are large at $\sim 1$ $\mu \mathrm{m}$ in diameter and are primarily located on the grain boundaries. Hence, their dissolution products will be more heterogeneously dispersed compared to the $\sim 60 \mathrm{~nm}$ sized $\mathrm{ZrFeCr}$ and $\mathrm{ZrFeNi}$ type SPPs found in Zircaloy-2. At distances exceeding $500 \mathrm{~nm}$ from the $\mathrm{Zr}_{3} \mathrm{Fe}$ SPPs there is no detectable Fe segregation in the matrix. Therefore, in the centre of a grain in $\mathrm{Zr}-0.1 \mathrm{Fe}$, away from any SPPs, no $\mathrm{Fe}$ segregation has been observed and therefore no irradiation-induced precipitation, 
Figure 8 . This is in contrast to the proton-irradiated Zircaloy-2 material, in which Fe segregation is observed throughout the grain at 4.7 dpa due to each SPP undergoing more significant dissolution.

It must be acknowledged that $\mathrm{Fe}$ content is not the only difference between the $\mathrm{Zr}$ $0.1 \mathrm{Fe}$ alloy and Zircaloy-2. The behaviour of $\mathrm{Cr}$ and $\mathrm{Ni}$ is assumed here to be similar to Fe as both are considered to be interstitial alloying elements [51] and have been seen to segregate to the same regions as Fe $[18,26]$. The influence of Sn on IIG has been investigated by Zee and Rogerson using Zr-Sn alloys neutron-irradiated in the DIDO reactor with a flux of $7.5 \times 10^{17} \mathrm{n} \mathrm{m}^{-2}[52,53]$. At $80{ }^{\circ} \mathrm{C}$ the $\mathrm{Zr}-1.5 \mathrm{Sn}$ alloy resulted in less IIG than the $\mathrm{Zr}-1.0 \mathrm{Sn}$ sample. However at $280{ }^{\circ} \mathrm{C}$ the reverse was observed such that the IIG strain of $\mathrm{Zr}-0.1 \mathrm{Sn}<\mathrm{Zr}-1.5 \mathrm{Sn}$ [52]. The mechanism proposed was that the $\mathrm{Sn}$, which remains in solution and did not form SPPs, acts as a vacancy trap at low temperatures but not at high temperatures. These $\mathrm{Zr}$-Sn binaries exhibited more IIG strain than Zircaloy-2, suggesting the other minor alloying elements are having a significant effect [53]. From these observations, one could predict that at high temperatures, $>280^{\circ} \mathrm{C}$, more $\mathrm{Sn}$ in an alloy should lead to increased IIG and therefore higher dislocation line density. However in the current work we show that Zircaloy-2, containing $1.5 \mathrm{wt} \% \mathrm{Sn}$, displays a lower overall a-loop line density and delayed c-loop nucleation than the $\mathrm{Zr}-0.1 \mathrm{Fe}$ alloy, which contains no Sn. This suggests Sn does not have a critical impact on dislocation formation, and hence IIG.

It is proposed that a significant difference between the two materials in the current work is the amount of Fe present in the matrix after SPP dissolution; therefore it is 
important to understand how such variable matrix chemistry affects dislocation loop evolution and how this relates to IIG. The most striking difference between $\mathrm{Zr}-0.1 \mathrm{Fe}$ (5 dpa) and Zircaloy-2 (4.7 dpa) is the size and line density $\left(\varrho_{\mathrm{LD}}\right)$ of a-loops, as shown in Figure 9. At 4.7 dpa, the major axis of the a-loops in Zircaloy-2 is $7.8 \pm 2.9 \mathrm{~nm}$ whereas at $5 \mathrm{dpa}$ in $\mathrm{Zr}-0.1 \mathrm{Fe}$ the major axis is $25.7 \pm 1.0 \mathrm{~nm}$. The a-loop $\varrho_{\mathrm{LD}}$ is a factor of $\sim 3$ higher for Zr-0.1Fe vs Zircaloy-2 at similar proton doses (5 and 4.7dpa). The overall $\varrho_{\mathrm{LD}}$ of a-loops in $\mathrm{Zr}-0.1 \mathrm{Fe}(5 \mathrm{dpa})$ is $3.69 \times 10^{14} \mathrm{~m}^{-2}$ and in Zircaloy-2 (4.7 dpa) is $1.14 \times 10^{14} \mathrm{~m}^{-2}$. Further, the onset of c-loop nucleation in $\mathrm{Zr}-0.1 \mathrm{Fe}$ occurs earlier than in Zircaloy-2 at $\sim 3$ and $\sim 4.7$ dpa, respectively. It is interesting to note that the standard deviation in the a-loop size for both alloys decreases at higher dose levels. This is due to a tendency towards loop uniformity and order, which may be due to the interaction of dislocation loop strain fields. The error bars (standard deviation) associated with the $3 \mathrm{dpa} \mathrm{Zr}-0.1 \mathrm{Fe} \mathrm{c}-$ loop $\varrho_{\mathrm{LD}}$ are large due to the variation in c-loop number density across a grain; some parts of a grain have a high density of c-loops whilst other parts have few. By 5 dpa the c-loops are more uniformly distributed throughout a grain. In comparing the two alloys, it appears that $\mathrm{Fe}$ segregation to basal plane traces in the matrix is associated with smaller, more organised a-loops with a lower $\varrho_{\mathrm{LD}}$ and a delay in c-loop nucleation.

\section{Effect of Fe on Irradiation Induced Growth}

Irradiation results in self-interstitial atom (SIA) and vacancy defects and their clusters, which coalesce and collapse to form dislocation loops [54,55]. Uncertainty surrounds the diffusion behaviour of point defects at the present moment in the literature. It has recently been described by Samolyuk et al. that both vacancy and SIA defects diffuse anisotropically, with a preference for both point defects to diffuse 
parallel to the basal plane [56]. However, the anisotropic diffusion of point defects, in different directions through the hexagonal close packed Zr matrix, has been proposed to better understand IIG-related phenomena $[1,57,58]$. The core of the differential anisotropic diffusion (DAD) theory, as discussed by Woo et al. [58], concerns the net diffusion of SIAs in the basal plane and vacancies in the $<c>$ direction [57]. Woo further discusses the importance of sink orientation with respect to the point defect diffusion anisotropy [58], such that a line defect acts as a sink when it is orientated perpendicular to a particular diffusion path. A defect that is elongated in the $<\mathrm{c}>$ direction would thereby act as a strong sink for SIAs and one elongated in the basal plane as a sink for vacancies. As seen in Figure 8(c), the irradiation-induced precipitation (IIP) observed in the present work aligns along the trace of the basal plane with $\sim 25 \mathrm{~nm}$ between each row of IIPs and spaced $\sim 9 \mathrm{~nm}$ apart from one another within each row. One may therefore consider the IIPs to act as a strong sink for defects diffusing in the $<c>$ direction and so have a sink bias for vacancies. The drop in a-loop $\varrho_{\mathrm{LD}}$ and the delay in c-loop nucleation is readily explained when the IIP is present, as fewer vacancies are available for both vacancy-type loop formation. This would suggest that there is a bias for interstitial a-loops, which has been suggested when comparing neutron-irradiated crystal-bar $\mathrm{Zr}$ and Zircaloy-2 at $427^{\circ} \mathrm{C}$ to a fluence of $1.1 \times 10^{25} \mathrm{n} \mathrm{m}^{-2}$ using EBR-II [25]. Griffiths et al. state that in crystal bar $\mathrm{Zr} 60 \%$ of a-loops are vacancy in nature. This is reduced to $50 \%$ with the addition of alloying elements in Zircaloy-2. However it must be noted that the ratio of vacancy and interstitial a-loops has been reported to vary from grain to grain [9], therefore there is a need for a macroscopic method for determining a-loop character in order to gain a true understanding of these variations. The proposal of the irradiation-induced 
precipitation acting as sinks for point defects does not rely on the notion of diffusion anisotropy, however it helps to explain the experimental observations.

In the past it has been theorised that increasing the Fe content in an alloy would lead to an increase in growth strain due to the stabilising effect of interstitial alloying elements on c-loop formation [16,17,51]. De Carlan et al. [16] used electronirradiation and Fe implantation on Zircaloy-4 300-450 $\mathrm{nm}$ thin samples to demonstrate an increased c-loop density at higher Fe contents. However the damage caused by the Fe-implantation was high, $\sim 55$ dpa for the maximum implantation level [16], which may explain the trend of increasing density and size of c-loops as a function of Fe implantation. To clearly understand this effect the total dpa from the Fe implantation and electron irradiation should be considered and not just the damage resulting in electron irradiation. However trends in IIG strain with variable Fe content have been reported in E635, irradiated in BOR-60 at 5-10 x 10 $0^{19} \mathrm{n} \mathrm{m}^{-2} \mathrm{~s}^{-1}$ [23]. At 0.3$0.65 \mathrm{wt} \% \mathrm{Fe}$, the alloy did not enter the breakaway growth regime and this delay continued to $\sim 30$ dpa when the test was stopped. Lowering the Fe content to 0.10-0.15 wt $\%$ resulted in breakaway growth at $\sim 15 \mathrm{dpa}$ [23]. The present work suggests that $\mathrm{Fe}$ nano-precipitation in the matrix reduces c-loop density, which suggests a reduction in growth strain.

An observation discussed by de Carlan et al. is the increased density of c-loops around SPPs [16], which suggests Fe helps c-loop nucleation. Figure 7 also clearly shows $\mathrm{Fe}$ and $\mathrm{Cr}$ segregation along the line of c-loops adjacent to a $\mathrm{Zr}(\mathrm{Fe}, \mathrm{Cr})_{2} \mathrm{SPP}$ in Zircaloy-2 under BWR conditions. The presence of c-loops in the vicinity of partiallydissolved SPPs is commonly thought to be due to a stabilising effect of Fe on c-loop 
nucleation $[16,17]$, as is confirmed by the nucleation of c-loops in impure $\mathrm{Zr}$ when compared to crystal bar [59]. It may be the case that c-loops form preferentially around an SPP to reduce the high local strain caused by the dissolution process. Away from an SPP, where the local strain is lower and IIP is able to occur, there is a delay in c-loop formation as there are more sites for vacancy annihilation. Likewise, Fe segregation to dislocation loops $[16,26,32]$ may be expected due to a simple strain field effect [17]. In the present work, an effect similar to that proposed for oxide dispersion strengthened (ODS) steels is observed by which widespread nanoprecipitates, $\sim 6-10 \mathrm{~nm}$ diameter, result in a decrease in observable damage structures and a reduced effect on mechanical properties after irradiation in comparison to nonODS steels [60-62]. It has been proposed that in yttria-based ODS steels the $\mathrm{Y}_{2} \mathrm{O}_{3}$ nano-particles act as a strong trap for both interstitial and vacancy point defects [63].

As vacancy c-loop density is positively correlated with IIG strain [10], one may expect higher Fe content to reduce growth strain, based upon the above observations and the preposition that the precipitates may act as a net vacancy sink. This has been supported in the recent work by Yagnik et al. [22], as part of the EPRI-led NFIR program. Growth data from a Zr-1.0Sn alloy with varying levels of Fe from 100-4000 ppm irradiated in the BOR-60 test reactor at $\sim 320^{\circ} \mathrm{C}$ with a neutron flux of $5-10 \times 10^{19}$ $\mathrm{n} \mathrm{m}^{-2} \mathrm{~s}^{-1}$ showed that, higher Fe content leads to a decrease in axial IIG strain [22]. Yagnik et al. noted that at the highest damage dose, STEM-EDS data shows the Zr1.0Sn-0.4Fe alloy contained more $\mathrm{Fe}$ in the matrix than $\mathrm{Zr}-1.0 \mathrm{Sn}-0.01 \mathrm{Fe}$ alloy by a factor of $\sim 3$ [22]. While Yagnik et al. make no mention of irradiation-induced precipitation it was not explicitly looked for. Recent atom probe tomography studies in Zircaloy-2 BWR clad demonstrate the clustering of $\mathrm{Fe}$ and $\mathrm{Cr}$ throughout the 
matrix [28] and nano-precipitation after test reactor experiments are well documented $[27,29]$. The observation that increasing Fe content in $\mathrm{Zr}-1.0 \mathrm{Sn}$ alloys leads to a reduction in axial growth strain, made by Yagnik et al. could be explained by the Fe nano-precipitation after SPP dissolution that is shown in the present work and the resultant high interfacial region surface area that acts as a point defect sink, particularly for vacancies due to the alignment of the IIP. At 4.1 dpa the growth strain of the 100 and 4000ppm Fe content samples are similar at $0.07 \%$ and $0.1 \%$ respectively. As the damage level increases the difference in growth strain between the alloys increases. At $33.7 \mathrm{dpa}$ an increased Fe content from 100 to $4000 \mathrm{ppm}$ results in a difference in growth strain of $2.68 \%$. The slight variation in growth strain at 4.1 dpa suggests that the early IIG stage is predominately governed by interstitial aloops, as the presence of the IIP may lead to a bias towards interstitial a-loop formation and the reduction in vacancy a-loops does not play a major role in this early growth regime. As the damage level moves into the breakaway growth regime the difference in IIG strain becomes large, with the lowest growth strain seen in the 4000 ppm sample. This may be due to a larger volume fraction of SPPs and therefore a higher volume fraction of IIP, assuming they are of similar size and distribution. This increased nano-precipitation would lead to a lower c-loop $\varrho_{\mathrm{LD}}$, which may correlate with the reduced growth strain.

\section{Conclusions}

By investigating the effects of proton irradiation on a model $\mathrm{Zr}-0.1 \mathrm{Fe}$ (wt\%) binary alloy and Zircaloy-2, the importance of Fe in microstructural evolution is highlighted and its potential effect on irradiation-induced growth (IIG) is discussed. 
- During both proton and neutron irradiation, Fe has been observed to dissolve from secondary phase particles (SPPs), diffuse through the matrix and form clusters/precipitates along the trace of the basal plane.

- These nano-precipitates appear to nucleate from pyramidal dislocation loops where Fe was detected. This precipitation is correlated with both a reduction in a-loop line density and a delay in c-loop nucleation.

- Observations of a lower a-loop line density and delayed c-loop nucleation in the presence of irradiation-induced precipitation have been documented. These nano-precipitates may act as new sites for point defect annihilation. These observations, coupled with growth data showing that increased $\mathrm{Fe}$ in the $\mathrm{Zr}$ $0.1 \mathrm{Sn}$ system leads to a decrease in IIG [22], suggests that redistributed Fe, facilitated by SPP dissolution/amorphisation, leads to a reduction in IIG.

- These results may be significant to alloy design as they suggest that increasing the amount of evenly dispersed Fe-containing SPPs, and thereby nanoprecipitates, may be an effective way to reduce the effects of IIG.

\section{Acknowledgements}

This work is funded by an EPSRC Leadership Fellowship for the study of irradiation damage in zirconium alloys [EP/I005420/1], with additional industrial contributions from National Nuclear Laboratory, Westinghouse, Rolls-Royce and Studsvik Nuclear. The authors would like to thank Gary Was and Ovidui Toader for their advice and use of the Michigan Ion Beam Laboratory for the proton irradiations. Finally, a special thanks to Mats Dahlbäck of Westinghouse Electric Sweden for continued enthusiasm with the study and many insightful discussions. 


\section{References}

[1] R.A. Holt, Mechanisms of Irradiation Growth of Alpha-Zirconium Alloys, J. Nucl. Mater. 159 (1988) 310-338.

[2] V. Fidleris, R.P. Tucker, R.B. Adamson, An Overview of Microstructural and Experimental Factors That Affect the Irradiation Growth Behavior of Zirconium Alloys, in: Zircon. Nucl. Ind. Seventh Int. Symp., 1987: pp. 49-85.

[3] D. Gilbon, A. Somiak, S. Doriot, J. Mardon, Irradiation Creep and Growth Behavior and Microstructural Evolution of Advanced Zr-Base Alloys, in: Zircon. Nucl. Ind. Twelfth Int. Symp., 2000: pp. 51-73.

[4] F. Onimus, J.L. Bechade, Radiation Effects in Zirconium Alloys, Compr. Nucl. Mater. 4 (2012) 273-246.

[5] D.O. Pickman, Interactions Between Fuel Pins and Assembly Components, Nucl. Eng. Des. 33 (1975) 125-140.

[6] R.B. Adamson, Effects of Neutron Irradiation on Microstructure and Properties of Zircaloy, in: Zircon. Nucl. Ind. Twelfth Int. Symp., 2000: pp. 15-31.

[7] G.J.C. Carpenter, D.O. Northwood, The Contribution of Dislocation Loops to Radiation Growth and Creep of Zircaloy-2, J. Nucl. Mater. 56 (1975) 260-266.

[8] C.H. Woo, Modeling Irradiation Growth of Zirconium and its Alloys, Radiat. Eff. Defects Solids. 144 (1998) 145-169.

[9] A. Jostsons, P.M. Kelly, R.G. Blake, The Nature of Dislocation Loops in Neutron Irradiated Zirconium, J. Nucl. Mater. 66 (1977) 236-256.

[10] R.A. Holt, R.W. Gilbert, c-Component Dislocations in Annealed Zircaloy Irradiated at about 570K, J. Nucl. Mater. 137 (1986) 185-189.

[11] R.W. Gilbert, Amorphous Intermetallics in Neutron Irradiated Zircaloys After High Fluences, J. Nucl. Mater. 135 (1985) 265-268.

[12] W.J.S. Yang, Precipitate Stability in Neutron-Irradiated Zircaloy-4, J. Nucl. Mater. 158 (1988) 71-80.

[13] M. Griffiths, R.W. Gilbert, The Formation of c-Component Defects in Zirconium Alloys During Neutron Irradiation, J. Nucl. Mater. 150 (1987) 169181.

[14] F. Garzarolli, W. Goll, A. Seibold, I. Ray, Effect of In-PWR Irradiation on Size, Structure, and Composition of Intermetallic Precipitates of $\mathrm{Zr}$ Alloys, in: 
Zircon. Nucl. Ind. Elev. Int. Symp., 1996: pp. 541-556.

[15] A. Harte, D. Jadernas, P. Frankel, J. Romero, L. Hallstadius, M. Preuss, A Comparison of Proton and Neutron Irradiation-Induced Microchemical Evolution in Zircaloy-2, Not Publ. (n.d.).

[16] Y. de Carlan, C. Regnard, M. Griffiths, Influence of Iron in the Nucleation of $<c>$ Component Dislocation Loops in Irradiated Zircaloy-4, in: Zircon. Nucl. Ind. Elev. Int. Symp., 1996: pp. 638-653.

[17] F. Christien, A. Barbu, Cluster Dynamics Modelling of Irradiation Growth of Zirconium Single Crystals, J. Nucl. Mater. 393 (2009) 153-161.

[18] A. Harte, T. Seymour, E.M. Francis, P. Frankel, S.P. Thompson, D. Jädernäs, et al., Advances in Synchrotron X-Ray Diffraction and Transmission Electron Microscopy Techniques for the Investigation of Microstructure Evolution in Proton- and Neutron-Irradiated Zirconium Alloys, J. Mater. Res. 30 (2015) 1349-1365.

[19] M. Griffiths, R.W. Gilbert, G.J.C. Carpenter, Phase Instability, Decomposition and Redistribution of Intermetallic Precipitates in Zircaloy-2 and -4 During Neutron Irradiation, J. Nucl. Mater. 150 (1987) 53-66.

[20] M. Griffiths, R.A. Holt, A. Rogerson, Microstructural Aspects of Accelerated Deformation of Zircaloy Nuclear Reactor Components During Service, J. Nucl. Mater. 225 (1995) 245-258.

[21] S. Valizadeh, G. Ledergerber, S. Abolhassan, D. Jädernäs, M. Dahlbäck, E. V Mader, Effects of Secondary Phase Particle Dissolution on the In-Reactor Performance of BWR Cladding, in: Zircon. Nucl. Ind. Sixtteenth Int. Symp., 2011: pp. 729-753.

[22] S. Yagnik, R.B. Adamson, G. Koblyansky, J.H. Chen, D. Gilbon, S. Ishimoto, et al., Zirconium in the Nuclear Industry: Eighteenth International Symposium, 2016.

[23] V.N. Shishov, M.M. Peregud, A. V Nikulina, G.P. Kobylyansky, A.E. Novoselov, Z.E. Ostrovsky, et al., Influence of Structure - Phase State of $\mathrm{Nb}$ Containing Zr Alloys on Irradiation-Induced Growth, in: Zircon. Nucl. Ind. Fourteenth Int. Symp., 2005: pp. 666-685.

[24] M. Griffiths, A Review of Microstructure Evolution in Zirconium Alloys During Irradiation, J. Nucl. Mater. 159 (1988) 190-218. 
[25] M. Griffiths, R.W. Gilbert, V. Fidleris, R.P. Tucker, R.B. Adamson, Neutron Damage in Zirconium Alloys Irradiated at 644 to 710K, J. Nucl. Mater. 150 (1987) 159-168.

[26] A. Harte, M. Topping, P. Frankel, M. Preuss, A Comparison of Proton and Neutron Irradiation-Induced Dislocation Loop Evolution and Associated Microchemical Changes in Zircaloy-2, Acta Mater. (2016) Submitted.

[27] O.T. Woo, G.J.C. Carpenter, Radiation-Induced Percipitation in Zircaloy-2, J. Nucl. Mater. 159 (1988) 397-404.

[28] G. Sundell, M. Thuvander, P. Tejland, M. Dahlback, L. Hallstadius, H.O. Andrenn, Redistribution of Alloying Elements in Zircaloy-2 After In-Reactor Exposure, J. Nucl. Mater. 454 (2014) 178-185.

[29] M. Griffiths, D. Gilbon, C. Regnard, C. Lemaignan, HVEM Study of the Effects of Alloying Elements and Impurities on Radiation Damage in $\mathrm{Zr}$ Alloys, J. Nucl. Mater. 205 (1993) 273-283.

[30] L. Hallstadius, S. Johnson, E. Lahoda, Cladding for High Performance Fuel, Prog. Nucl. Energy. 57 (2012) 71-76.

[31] R.E. Stoller, M.B. Toloczko, G.S. Was, A.G. Certain, S. Dwaraknath, F.A. Garner, On the Use of SRIM for Computing Radiation Damage Exposure, Nucl. Instruments Methods Phys. Res. B. 310 (2013) 75-80.

[32] S. Valizadeh, G. Ledergerber, S. Abolhassan, G. Zhou, J. Wright, L. Hallstadius, Effects of Secondary Phase Particle Dissolution on the In-Reactor Performance of BWR Cladding, (n.d.) 1-51.

[33] C. Toffolon-Masclet, J.-C. Brachet, G. Jago, Studies of Second Phase Particles in Different Zirconium Alloys Using Extractive Carbon Replica and an Electrolytic Anodic Dissolution Procedure, J. Nucl. Mater. 305 (2002) 224 231.

[34] J.D. Ardisson, R.A. Maneur, E.G. Silva, A study of structural and electronic properties of the alloy systems (Zr1-x Tix)2 Fe and (Zr1-x Tix)3 Fe in the range $0<=x<=0.2$, Scr. Mater. Mater. 25 (1991) 1327-1331.

[35] D.J. Dingley, Dislocation Invisibility in Dark-Field Electron Microscopy, Phys. Status Solidi B. 38 (1970) 345-355.

[36] P.R. Okamoto, E. Levine, G. Thomas, Kikuchi Maps for hep and bcc Crystals, J. Appl. Phys. 38 (1967) 289-296. 
[37] A. Jostsons, R.G. Blake, P.M. Napier, K. Farrell, Faulted loops in NeutronIrradiated Zirconium, J. Nucl. Mater. 68 (1977) 267-276.

[38] K. Thompson, D. Lawrence, D.J. Larson, J.D. Olson, T.F. Kelly, B. Gorman, In Situ Site-Specific Specimen Preparation for Atom Probe Tomography., Ultramicroscopy. 107 (2007) 131-9.

[39] P.. Warren, A. Cerezo, G.D.. Smith, Observation of Atomic Planes in 3DAP Analysis, Ultramicroscopy. 73 (1998) 261-266.

[40] V.N. Shishov, A.V. Nikulina, A. Vladimir, Influence of Neutron Irradiation on Dislocation Structure and Phase Composition of Zr-Base Alloys, in: Zircon. Nucl. Ind. Elev. Int. Symp., 1996: pp. 603-621.

[41] A.T. Motta, L.M. Howe, P.R. Okamoto, Amorphization Kinetics of Zr3Fe Under Electron Irradiation, J. Nucl. Mater. 205 (1993) 258-266.

[42] L.M. Howe, D. Phillips, A.T. Motta, P.R. Okamoto, Irradiation-induced Phase Transformations in Zirconium Alloys, Surf. Coatings Technol. 66 (1994) 411418.

[43] A. Harte, M. Topping, P. Frankel, D. Jadernas, L. Hallstadius, E.C. Darby, et al., Nano-Scale Chemical Evolution in a Proton- and Neutron-Irradiated Zr Alloy, J. Nucl. Mater. (2016) Submitted.

[44] X.T. Zu, K. Sun, M. Atzmon, L.M. Wang, L.P. You, F.R. Wan, et al., Effect of Proton and Ne Irradiation on the Microstructure of Zircaloy 4, Philos. Mag. 85 (2005) 649-659.

[45] Y. Idrees, E.M. Francis, Z. Yao, A. Korinek, M. a. Kirk, M. Sattari, et al., Effects of Alloying Elements on the Formation of c-component Loops in $\mathrm{Zr}$ Alloy Excel Under Heavy Ion Irradiation, J. Mater. Res. 30 (2015) 1310-1334.

[46] A.T. Motta, Amorphization of Intermetallic Compounds Under Irradiation A Review, J. Nucl. Mater. 244 (1997) 227-250.

[47] M. Griffiths, M.H. Loretto, R.E. Smallman, Electron Damage in Zirconium, J. Nucl. Mater. 115 (1983) 323-330.

[48] W.J.S. Yang, R.P. Tucker, B. Cheng, R.B. Adamson, Precipitates in Zircaloy: Identification and the Effects of Irradiation and Thermal Treatment, J. Nucl. Mater. 138 (1986) 185-195.

[49] Y. Etoh, S. Shimada, Neutron Irradiation Effects on Intermetallic Precipitates in Zircaloy as a Function of Fluence, J. Nucl. Mater. 200 (1993) 59-69. 
[50] Y. Etoh, S. Shimada, Irradiation-Induced Dissolution of Precipitates in Zircaloy-2, J. Nucl. Sci. Technol. (1992) 358-366.

[51] M. Christensen, W. Wolf, C.M. Freeman, E. Wimmer, R.B. Adamson, L. Hallstadius, et al., Effect of Alloying Elements on the Properties of $\mathrm{Zr}$ and the Zr-H system, J. Nucl. Mater. 445 (2014) 241-250.

[52] R.H. Zee, A. Rogerson, G.J.C. Carpenter, J. Watters, Effect of Tin on the Irradiation Growth of Polycrystalline Zirconium, J. Nucl. Mater. 120 (1984) $223-229$.

[53] A. Rogerson, R.H. Zee, Irradiation Growth in Zirconium-Tin Alloys at 353 and 553K, J. Mater. Res. 152 (1988) 220-224.

[54] C. Varvenne, O. Mackain, E. Clouet, Vacancy Clustering in Zirconium: An Atomic-Scale Study, Acta Mater. 78 (2014) 65-77.

[55] S.J. Wooding, L.M. Howe, F. Gao, A.F. Calder, D.J. Bacon, A molecular dynamics study of high-energy displacement cascades in a -zirconium, J. Nucl. Mater. 254 (1998) 191-204.

[56] G.D. Samolyuk, A. V. Barashev, S.I. Golubov, Y.N. Osetsky, R.E. Stoller, Analysis of the Anisotropy of Point Defect Diffusion in hcp Zr, Acta Mater. 78 (2014) 173-180.

[57] C.H. Woo, Theory of Irradiation Deformation in Non-Cubic Metals: Effects of Anisotropic Diffusion, J. Nucl. Mater. 159 (1988) 237-256.

[58] C.H. Woo, Defect Accumulation Behaviour in HCP Metals and Alloys, J. Nucl. Mater. 276 (2000) 90-103.

[59] M. Griffith, R.W. Gilbert, C.E. Coleman, Grain Boundary Sinks in NeutronIrradiated Zr and Zr-Alloys, J. Nucl. Mater. 159 (1988) 405-416.

[60] G.R. Odette, M.J. Alinger, B.D. Wirth, Recent Developments in IrradiationResistant Steels, Annu. Rev. Mater. Res. 38 (2008) 471-503.

[61] R. Schaublin, A. Ramar, N. Baluc, V. de Castro, M.A. Monge, T. Leguey, et al., Microstructural Development Under Irradiation in European ODS Ferritic/Martensitic Steels, J. Nucl. Mater. 351 (2006) 247-260.

[62] S. Ukai, M. Fujiwara, Perspective of ODS Alloys Application in Nuclear Environments, J. Nucl. Mater. 307-311 (2002) 749-757.

[63] J. Brodrick, D.J. Hepburn, G.J. Ackland, Mechanism for Radiation Damage Resistance in Yttrium Oxide Dispersion Strengthened Steels, J. Nucl. Mater. 
445 (2014) 291-297. 